\title{
Comparison of clinical presentation between Chronic Otitis Media Mucosal with Squamous.
}

\author{
Shrestha $B L^{1}$, Shrestha $\mathrm{I}^{2}$, Amatya $\mathrm{RC}^{3}$
}

1-3 Department of ENT-HNS,

Dhulikhel Hospital - Kathmandu University Hospital,

Dhulikhel, Nepal.

\section{Corresponding Author}

Dr Bikash Lal Shrestha

Department of ENT-HNS,

Dhulikhel Hospital - Kathmandu University Hospital,

Dhulikhel, Nepal.

Email. bikash001@hotmail.com

Kathmandu Univ Med J 2010;9(32):387-91

\begin{abstract}
Background

Chronic otitis media is a chronic inflammatory disease of the middle ear cleft which is manifested as deafness and ear discharge. It is a common condition affecting 0.5 $-30 \%$ of any community worldwide, and most common in developing countries. The prevalence mainly depends on age, low socio-economic status, overcrowding and limited medical facilities.
\end{abstract}

\section{Objective}

To compare the clinical presentation between chronic otitis media mucosal with squamous types.

\section{Methods}

A prospective, longitudinal and analytical study performed among 200 patients who have features of chronic otitis media and were attended to in the ear, nose and throat outpatient department of Dhulikhel Hospital - Kathmandu University Hospital, Dhulikhel, Nepal from January 2010 to January 2011. Patients who had already undergone surgery and came back to the hospital, with inadequate information were excluded from the study.

\section{Results}

The results showed that, out of 200 cases, 120 (60\%) were chronic otitis media- mucosal and $80(40 \%)$ were chronic otitis media - squamous. Patients $<30$ years were affected in both groups. The male to female ratio in chronic otitis media mucosal was 1.14:1, whereas in chronic otitis media squamous, it was 1.96:1. Similarly in etiological factors, oil and water exposure (76\%) was the most common cause in chronic otitis media mucosal, whereas in chronic otitis media squamous, oil and water exposure (62.5\%) and recurrent upper respiratory tract infection (62.5\%) were the most common causes. Of all the clinical features, ear discharge was the leading feature in both chronic otitis media mucosal $(98 \%)$ and squamous $(100 \%)$ cases. The complications were mainly seen in the chronic otitis media squamous and the most common complication was mastoid abscess (5\%).

\section{Conclusions}

The frequency of chronic otitis media is higher in the younger age group and those lacking in health education. As a result, it is important to disseminate the health education regarding the ear disease which will help in decreasing the frequency of the disease in developing countries like ours.

\section{Key Words}

chronic otitis media, mastoid abscess, upper respiratory tract infection 


\section{INTRODUCTION}

Chronic otitis media (COM) is a chronic inflammatory disease of the middle ear cleft which is complicated as partialortotallossofthetympanicmembraneandossicles andalsocausesirreversiblesequelaewhichismanifestsas deafnessandeardischarge. ${ }^{1,2}$ This diseaseisclassifiedinto healed COM, COM (mucosal) active and inactive, COM (squamous) active and inactive as the old terminology ofchronicsuppurativeotitismediatubo-tympanicand attico-antral has been abandoned. ${ }^{3} \mathrm{COM}$ is a common condition affecting $0.5-30 \%$ of any community. It is mostcommonindeveloping countries.Theprevalencein ourcountryis $3.5 \% .{ }^{4}$ Theprevalencemainlydependson age,lowsocio-economicstatus,overcrowdingandlimited medical facility. ${ }^{2,5}$

TheCOMmucosalischaracterised byeitherpermanent perforationoftheparstensawithoutinflammationofthe middleearandmastoidifitisinactive.Inactivecases, there ischronicinflammation withinthemucosaofthemiddle earandmastoid,characterisedbyintermittentandmainly mucoidormucopurulentdischargewhichisprecipitated byupperrespiratorytractinfectionandentryofwateror oil instillation. ${ }^{6}$

The COM squamous is characterised by only the retraction pocketinthetympanicmembraneifinactive typesandinactivetypesthereischolesteatomawithinthe tympanicmembrane. ${ }^{6}$ Thereisacontinuousfoulsmelling dischargeincases ofCOMsquamous, and thechance of complications is higher than that of COM mucosal.

The various complications associated with COM squamousaremastoiditis, labyrinthitis, varioustypesof subperiostealabscess,facialnerveparalysisandpetrositis. Intracranialcomplicationsincludemeningitis, extradural abscess, subdural abscess, brain abscess, lateral sinus thrombophlebitisandotitichydrocephalus. ${ }^{7}$ However, these complications are also seen in COM mucosal but less frequently.

The main aim of our study is to compare the clinical presentationbetweenCOMmucosalwiththesquamous type.

\section{METHODS}

This study is a prospective, longitudinal and analytical studyperformedamong200patientswhohavefeaturesof COMattended inear, noseand throat (ENT) outpatient departmentofKathmanduUniversityHospital,Dhulikhel, Nepalfrom January2010toJanuary2011.Patientswho had already undergone surgery prior to their hospital consultation, and/orreceivedlittleornoinformationwere excludedfromthestudy. Theresultswereanalysedusinga simple manual analysis of frequency and percentage.

\section{RESULTS}

200 cases ofCOMwereincludedinthestudy. Ofthe 200 cases $120(60 \%)$ were COM mucosal and $80(40 \%)$ were COM squamous as shown in Table 1. Tables 2, 3, 4, 5, 6 and7showage, sexdistribution, theetiologicalfactors, clinical features and complications are shown in.

Table 1. Distribution of types of COM. $(n=200)$

\begin{tabular}{ll}
\multicolumn{1}{c}{ Types } & \multicolumn{1}{c}{ Number $(\mathbf{n = 2 0 0 )}$} \\
COM-mucosal & $120(60 \%)$ \\
CSOM-squamous & $80(40 \%)$
\end{tabular}

Table 2. Age distribution of patients in both COM mucosal and squamous.

\begin{tabular}{ccc|} 
Age group(years) & COM mucosal $(\mathbf{n = 1 2 0})$ & coM squamous $(\mathbf{n = 8 0})$ \\
$0-10$ & $40(34 \%)$ & $7(8.3 \%)$ \\
$11-20$ & $26(22 \%)$ & $26(33.3 \%)$ \\
$21-30$ & $35(29 \%)$ & $20(25 \%)$ \\
$31-40$ & $5(4 \%)$ & $13(16.7 \%)$ \\
$41-50$ & $3(2 \%)$ & $7(8.3 \%)$ \\
$>50$ & $11(8 \%)$ & $7(8.3 \%)$ \\
\end{tabular}

Table 3. Sex distribution of patients in both COM mucosal and squamous

$\begin{array}{ccc}\text { Sex } & \text { COM mucosal }(n=120) & \text { COM squamous }(n=80) \\ \text { Male } & 64(53.3 \%) & 53(66.3 \%) \\ \text { Female } & 56(46.7 \%) & 27(33.7 \%)\end{array}$

Table 4. Distribution of etiological factors in both COM mucosal and squamous

\begin{tabular}{lcc} 
Etiological factors & COM mucosal(n=120) & COM squamous(n=80) \\
\hline Over crowding & $3(2.2 \%)$ & - \\
Oil/water instillation & $91(76 \%)$ & $50(62.5 \%)$ \\
LPR & $3(2.2 \%)$ & - \\
Bottle feeding & $13(11 \%)$ & - \\
Recurrent URTI & $16(13 \%)$ & $50(62.5 \%)$ \\
Family h/o CSOM & $33(27 \%)$ & $10(12.5 \%)$ \\
No factors & $5(4 \%)$ & $20(25 \%)$
\end{tabular}

Table 5. showing distribution of clinical features in COM mucosal.

\begin{tabular}{cc} 
Clinical features & COM mucosal $(\mathbf{n = 1 2 0})$ \\
\hline Ear discharge & $117(98 \%)$ \\
Decrease hearing & $97(80.7 \%)$ \\
Earache & $16(13.5 \%)$ \\
Tinnitus & $7(5.7 \%)$ \\
Itchiness & $5(3.8 \%)$ \\
Vertigo & -
\end{tabular}


Table 6. Distribution of clinical features in COM squamous.

\begin{tabular}{cc} 
Clinical features & COM squamous $(\mathbf{n}=80)$ \\
\hline Ear discharge & $80(100 \%)$ \\
Decrease hearing & $75(93.7 \%)$ \\
Earache & $25(31.2 \%)$ \\
Tinnitus & $15(18.7 \%)$ \\
Vertigo & $3(3.7 \%)$ \\
Diplopia & $1(1.2 \% 0$ \\
Vomiting & $1(1.2 \%)$ \\
Headache & $1(1.2 \%)$ \\
Fever & $5(6.2 \%)$ \\
Cholesteatoma & $70(87.5 \%)$ \\
Polyp & $15(18.7 \%)$ \\
Mastoid abscess & $4(5 \%)$
\end{tabular}

Table 7. Distribution of complications in COM squamous.

\begin{tabular}{cc}
\hline Complications & COM squamous $(\mathbf{n}=80)$ \\
\hline Mastoid abscess & $4(5 \%)$ \\
\hline Petrositis & $1(1.2 \%)$ \\
Meningitis & $1(1.2 \%)$ \\
Labyrinthitis & $1(1.2 \%)$ \\
Lateral sinus thrombosis & $1(1.2 \%)$ \\
\hline
\end{tabular}

\section{DISCUSSION}

TheCOMismoreprevalentindeveloping countries rangesfrom 0.5-30\%. ${ }^{8}$ Mainlytheaffectedgroupsare lowsocio-economiccondition,youngagegroupand with family history of COM. ${ }^{9}$

Our study showed that the COM mucosal was $120(60 \%)$ and squamous 80 (40\%). The majority of patients were of COM mucosal, which may be because in mucosal diseases there is profuse ear discharge, and as a result patients are more likely to visit the hospital more frequently. However, in squamousvariety, dischargeisminimaland patients tendnottovisitthehospitaluntilthedischargebegins to smell or until there are complications.

Regarding the age group, patients of $<40$ years were most commonly affected with about $89 \%$ in COM mucosal and $83.3 \%$ in COM squamous whichcontrastswiththestudyperformed bytheUK NationalstudyofHearingwhichreportedindividuals inthe41-80yearagegroupweretwiceaslikelytohave COMasthoseaged $18-40$ years. ${ }^{10}$ However, results fromthisstudycorrelatewiththestudyperformedby Islametal,FakiretalandSiddiqueandKhan. ${ }^{11-13}$ This contrasts with theagegroup of thestudyin theUK whichcould bebecausetherearetraditionaltrends whicharespecifictoNepal.Forexample, pouringoil intotheearcanalduring childhoodisstillthoughtby sometowork.andyoung peoplefrequentlyswimin the river or pond water without aural protection.

As for the gender distribution, our study showed that the male sex were more commonly affected with male to femaleratio of 1.14:1 in COMmucosal and 1.96:1 in COM squamous which is similar to a study performed by Siddique and Khan, Islam et al. ${ }^{11,13}$ but thecontrast withthestudyperformed by the UK National Study of Hearing which showed nodifferencebetweenmaleandfemale. ${ }^{10}$ Thisresult in our study could be because Nepal is arguably a male-dominatedsociety.Generallyspeaking,menin the family are the head of the household, and they are more aware of their health than women of the household.Asaresult, theirhealthisprioritisedover women's.Otherfactorswhichmayaffectthemaleto femaleratioinNepalisthatmenaremorelikelytogo swimminginpublicplacessuchasrivers, ratherthan women.Themalearemoreawarewiththeirhealth than femalesand they also think that theymust be healthyas they are the earnersin the family. Other reasonmaybemalesmoreoftentakebathandswim in river.

Inetiologicalfactors, ourstudyshowed thatoiland water exposure accounts for $76 \%$ of the cases and was mostly responsible for COM mucosal., Other factorsincludethepatient'sfamilyhistory ofCOM, bottle feeding, recurrent URTI, overcrowding and laryngo-pharyngeal reflux (LPR). Similarly, in COM squamous, the oil and water instillation, recurrent URTI and family history of COM are mainlyresponsible.Oilandwaterexposurewasthe main cause of COM in our study as oil instillation is a traditional - method in our country during childbirth.Thestudyalsofoundthatwaterexposure wasamajorcause forCOMaspeople often swimin the rivers in Nepal without protection. Elsewhere, patient's with a family history of COM - were also prone to suffering from it as there have beencases of cross-contamination ofinfectionsamongfamily members.Bottlefeeding becameafactorasbottlefed children had lower immunity as compared to children who werefed breast milk. RecurrentURTI causestransienteustachiantubedysfunctionandalso themucosaofeustachiantubecontinuouswiththat ofmiddleearmucosawhichcausestransmission of infection. ${ }^{14}$ Ourstudyshowedthatovercrowdingwas alsoresponsibleforcausingCOMasitcorrelateswith thelowsocio-economicstatus asseen inthestudy carriedbySiddiqueandKhan, andlslametal,Bennett andHaggardstudy. ${ }^{11,13,15}$ Ourstudyshowedthat $2.2 \%$ had history ofLPR, the causal relation could belike that of study performed by Poelmans et al. ${ }^{16}$ 
The most common clinical presentation of COM mucosal in our study was ear discharge $(98 \%)$ and decreased hearing (80.7\%). Similarly other presentationswereearache,tinnitusanditchiness. Thesefindingsweresimilartothestudyperformed bylslametal,Kang etalandWeilingaetal. ${ }^{13,17,18}$ The slightdifferenceinourstudywasthateardischarge wasthemain presentation inourpatients.Itmaybe becausepatientsweremoreannoyedbythedischarge in the ear rather than hearing loss.

ThemostcommonpresentationofCOMSquamous waseardischarge(100\%), decreasehearing(93.7\%) andearache(31.2\%).Thepresentationsinourstudy is similar to that of Islam etal and Meimaneh et al ${ }^{13,}$ ${ }^{19}$ Butdiffersfromthestudy performed byWeilinga etal ${ }^{18}$ which showed hearingloss (83\%) to be more common than ear discharge (56\%).

Thecholesteatomatousfindingswere $87.5 \%$ inour study which is comparable to the study carried out by Islam et al ${ }^{13}$ which showed $76.6 \%$, but more than that of the study conducted by Meimaneh et $\mathrm{al}^{19}$ showing frequency of $42 \%$ only. Theincreased cholesteatomatous finding in our study could be becauseofnoseblowinghabitinourpatientswhich lead to change in middle ear pressure.

TherewerenocomplicationsinCOMmucosalcases inourstudywhereasinCOMSquamoustherewere total8(9.8\%)complicationsoutof80cases.Themost commoncomplicationswasmastoidabscess (5\%) whichissimilartostudyperformedbylslametaland OsmaUetal ${ }^{13,20}$ whereasothercomplicationswere meningitis, labyrinthitis, petrositisandlateralsinus thrombophlebitis.Thefrequency of complication more in COM squamous which is similar to study performed by Youngs et al. ${ }^{5}$ There were no deaths reported because of complications in our study.

\section{CONCLUSION}

Theresultsconcluded thatthefrequency ofCOMoccurs more in younger patients and those lacking health education. Thus, it is important to first tackle health education regarding ear diseases which will help in decreasing thefrequency ofthediseasefirstly.Similarly, earlydiagnosisandinterventioncouldpreventthedreadful complications of ear disease.

\section{REFERENCES}

1. Merchant SN, McKenna MJ, Rosowski JJ. Current status and future challenges of tymapnoplasty. Eur Arch Otorhinolaryngol 1998;255;221-8.

2. ShenoiPM.Mnagementofchronicsuppurativeotitismedia. In:BoothJB,editor.Scott-Brown'sOtolaryngology,5thed. Vol 3. London:Butter worth, 1987.p.215-31.

3. Browning GG. Aetiopathology of inflammatory conditions of the external and middle ear. In: Kerr AG Scott-Brown's Otolaryngology. 6th ed. Vol 3. London: Arnold;1997.p.18-21.

4. Adhikari P, Sinha BK, Pokhrel NR, Kharel B, Aryal R, Ma J.Prevalenceofchronicsuppurativeotitismediainschool children of Kathmandu district. J Inst Med 2007;29:10-2.

5. Youngs R. Chronic suppurative otitis media-mucosal disease.LundmanH.Diseaseoftheear,6thedition,Arnold 1988;27:374-385.

6. Browning GG, Merchant SN, Kelly G, Swan IR, Canter $R$ and McKerrow WS. Chronic otis media. In: Gleeson $M$,editor. Scott-Brown's Otolaryngology, 7th ed. Vol 3. London:Arnold;2008.p.3396-3401.

7. PandaNK,SreedharanS,MannSB,SharmaSC.Prognostic factors in complicated and uncomplicated chronic otits media. Am J Otolaryngol 1996;17:391-6.

8. SadeJ.Introduction.In:SadeJ,editor.Cholesteatomaand mastoid surgery. Amsterdam:Kugler;1982.p.1-3.

9. Hossain MM, Kundu SC, Haque MR. Shamsuzzaman AK, KhanMK,HalderKK.Extracranialcomplicationsofchronic suppurativeotitismedia.MymensinghMedJ2006;15:4-9.

10. BrowningGG,GatehouseS.Theprevalenceofmiddleear diseaseintheadultBritishPopulation.ClinicalOtolaryngol 1992;17:317-21.

11. Siddique $\mathrm{BH}$ and Khan $\mathrm{AH}$. Chronic suppurative otitis media- a rural area based study. SSMCJ 1995;3:12-16. 
12. Fakir AY, Hanif A, Ahmed KU, Haroon A. Intra-cranial complications ofCSOMa study of 40 cases. Bangladesh J Otolaryngol 1999; 5:11-14.

13. Islam MR, Taous A, Hossain MM, Ekramuddaula AFM, Islam MS. Comparative study of tutotympanic and atticoantral variety of chronic suppurative otits media. Bangladesh J Otorhinolaryngol 2010;16;113-9.

14. Winther B, Hayden FG, Arruda E, Dutkowski R, Ward P, Hendley JO.Viral respiratoryinfection in schoolchildren: effectsonmiddleearpressure.Paediatrics2002;109:826-32.

15. Bennett KE, Haggard MP. Accumulation of factors influencingchildren'smiddleeardisease:riskfactormodeling onalargepopulationcohort.JournalofEpidemiologyand Community health 1998;52:786-93.

16. PoelmansJ,TackJ,FeenstraL.Chronicmiddleeardisease andgastroesophagealrefluxdisease:acausalrelation?Otol Neurol 2001;22:447-50.

17. KangSanurilJ.Extracranialandintracranialcomplicationof suppurativeotitismediareportof 102 casesinThailand.J Laryngol otol 1993;107:999-1004.

18. Wielinga EW, Derks AM, Cremers CW. Tympanosclerosis in tympanic membrane: influence on outcome of myringoplasty. Am J Otol 1995;16:811-4.

19. MeimanehJA,HosseinnejadAF,ArabkhaniR,Hosseinnejad AS.Evaluationofcholesteatomafrequencyinpatientswith chronicotitismedia.ThelranianJournalofOtorhinolaryngol 2010;22:21-4.

20. Osma U, Cureoglu S. The complications of chronic otitis media:reportof93cases.JLaryngolOtol2000;114:97-100. 